Vol.61: e18160483, 2018

http://dx.doi.org/10.1590/1678-4324-2018160483

ISSN 1678-4324 Online Edition
BRAZILIAN ARCHIVES OF

BIOLOGY AND TECHNOLOGY

AN INTERNATIONAL JOURNAL

\title{
Can lychee reducing the adipose tissue mass in rats?
}

\author{
Martha Elisa Ferreira de Almeida ${ }^{1 *}$, Juliana Thays Ferreira ${ }^{1}$, Thalita Riquelme Augusto- \\ Obara $^{2}$, Richtier Gonçalves da Cruz ${ }^{2}$, Henrique Silvano Arruda ${ }^{3}$, Virgínia Souza Santos ${ }^{1}$, \\ José Antônio de Souza Cruz Ramos ${ }^{4}$, Diego Alvarenga Botrel ${ }^{5}$, Regiane Victória de Barros \\ Fernandes Botrel ${ }^{5}$ \\ ${ }^{I}$ Universidade Federal de Viçosa, Campus Rio Paranaíba, Rio Paranaíba, Minas Gerais, Brasil; ${ }^{2}$ Universidade de \\ São Paulo - Escola Superior de Agricultura Luiz Queiroz, Piracicaba, São Paulo, Brasil; ${ }^{3}$ Universidade Estadual de \\ Campinas, Campinas, São Paulo, Brasil; ${ }^{4}$ Perito Ambiental da Comarca de Rio Paranaíba, Rio Paranaíba, Rio \\ Paranaíba, Minas Gerais, Brasil; ${ }^{5}$ Universidade Federal de Lavras, Lavras, Minas Gerais, Brasil.
}

\begin{abstract}
Lychee fruit has been studied owing to the presence of several bioactive compounds that can contribute to weight loss in obese individuals. However, the anti-obese potential of the fruit has not been explored yet. The aim of this study was to investigate the effect of different parts of lychee in reducing the adipose tissue mass of cafeteria diet-fed rats. Phenolic compounds and scavenging capacities were quantified. The food intake, apparent digestibility, weight of the body and liver, body mass, Lee Index, and the mass of epididymal and visceral adipose tissues were evaluated. The results were estimated by Tukey's Test at 5\% probability. A higher amount of phenolic compounds and scavenging capacity were observed in the peel of lychee as compared to the other parts of the fruit. The hypercaloric diet with lychee flour resulted in a higher apparent digestibility. There was no difference between groups control $(C)$, hypercaloric $(\mathrm{H})$, hypercaloric with lychee flour $-50.00 \%$ peel and $50.00 \%$ seeds $(\mathrm{H} 2 \mathrm{~F})$, and hypercaloric with lychee flour - 33.33\% peel, 33.33\% pulp and 33.34\% seeds $(\mathrm{H} 3 \mathrm{~F})$ with respect to body and liver weight, corporal mass, and Lee Index. The hypercaloric diet-fed group exhibited an increase in visceral and epididymal adipose tissue mass, whereas the group fed with hypercaloric diets and flour made from the peel and seed of lychee presented a lower visceral adipose tissue mass. In conclusion, the use of lychee flour was considered viable because it decreased visceral adipose tissue mass in rats.
\end{abstract}

Key words: Phenolics, Cafeteria diet, Obesity, Litchi chinensis Sonn.

*Author for correspondence: martha.almeida@ufv.br 


\section{INTRODUCTION}

Obesity is one of the main challenges faced in practical clinic and is recognized as a complex pathology associated with risk factors such as coronary disease, several types of cancer, and type 2 diabetes ${ }^{1,2}$. The high prevalence of obesity causes economic consequences related to direct and indirect medical costs, since it is associated with the risk of develop diseases that decrease the quality and life expectancy ${ }^{3}$. This fact has contributed to the search for mechanisms involved in the body weight control, through experimental animals model fed with cafeteria diet, promoting weight gain by consumption of highly palatable and energetic foods which are an important part of the eating habits of the occidental population ${ }^{3}$.

The cafeteria diets supply can be started at the $7^{\text {th }}$ day after birth, after weaning or when adults. The total body weight gain of an animal subjected to this diet is approximately 30 to $40 \%$, and of the 12 weeks study that results in an increase of visceral fat amount, blood pressure, insulin resistance and hyperleptinaemia. Even when this diet does not promote an increase on body weight, its provision may result in changes on glucose and lipid metabolism and endothelial function ${ }^{4}$.

Currently we have been concerned with healthy eating in order to improve or maintain the health of the population. Combined with the scientific advances and backed up in the nutritional properties of food and its potential beneficial effects on human health preventing and treating diseases, some exotics tropical fruits have been considered as health promoting and very important to maintain life quality.

The lychee is a subtropical plant which is an evergreen shrub or tree, $10-12 \mathrm{~m}$ high with a broad round-topped crown of glossy green foliage ${ }^{5}$. Lychee (Litchi chinensis Sonn) is an exotic fruit that has been studied owing to the presence of several bioactive compounds $^{6}$ that can contribute to weight loss. The peel and seed are rich in antioxidants such as ascorbic acid, phenolic compounds (gallic acid), flavonoids (epicatechin, procyanidin B2 and procyanidin B4), and anthocyanins (cyanidin-3glucoside, cyanidin 3-rutinoside, quercetin 3-glucoside and quercetin 3-rutinoside), and the by-products of the lychee have various effects including anti-hyperlipidemic, antihyperglycemic, anti-inflammatory, hepatic and cardioprotective ${ }^{6}$.

The fruit has a sweet odor of rose and traditionally are used as tonic to heart, brain and liver ${ }^{5}$ due to their abundant polyphenols and flavonoids. Because of its attractive color and delicious taste, lychee has been widely accepted by consumers ${ }^{7}$. The possibility of developing a potential food ingredient capable of preventing obesity and retarding lipid oxidation from lychee is significant ${ }^{8}$.

The lychee besides having a pulp very nutritious, generating $50 \%$ of residue which is represented by the peel and seed. Such residues have high nutritional value and can be suitable as an alternative source of nutrients through the flour ${ }^{9}$. Thus, it is expected that the various molecules present in lychee meal prepared from the peel, pulp and seed, promotes a reduction in body weight and the adipose tissues of animals.

The aim of this study was to investigate the effect of different parts of lychee in reducing the adipose tissue mass of cafeteria diet-fed rats.

\section{MATERIAL AND METHODS}

\section{Lychee flour}

Lychee fruits were obtained from a farm located in São Gotardo (Minas Gerais, Brazil). The fruits were washed under running water to remove surface dirt and were sanitized with active chlorine (200ppm) for 10 minutes, followed by immersion in water for 2 minutes to remove excess chlorine. Next, the water was drained and the fruits were separated manually into different parts (peel, pulp and seed). These parts were dried in 
an oven with air circulation at $55^{\circ} \mathrm{C}$ for $4-6$ days, until a constant weight was obtained ${ }^{6}$. The dried fractions were ground in a domestic blender. The flours obtained were stored at room temperature $\left(25^{\circ} \mathrm{C}\right)$ in amber flasks until their use in the diet of Wistar rats.

\section{Content of phenolic compounds and scavenging capacity}

The ground samples of the three portions of the fruit (peel, seed and pulp) were dissolved in a solvent (ethanol 50\%) in a ratio of 1:30 (w/w). The compounds were extracted by heating the sample in glass tubes at $50^{\circ} \mathrm{C}$, in a water bath, with intermittent mixing at 200rpm for 50 minutes. These extracts were separated by centrifugation at $5000 \times g$ for 20 minutes. The samples were then filtered and stored in opaque airtight containers at $-26^{\circ} \mathrm{C}$ until further analysis.

The content of phenolic compounds in lychee flour was determined by FolinCiocalteu $^{10}$, using gallic acid as standard. $20 \mu \mathrm{L}$ of the diluted extract of lychee at concentration of 1:20 (v/v) was transferred to a test tube and $100 \mu \mathrm{L}$ of the FolinCiocalteau solution at $10 \%$ were added. After five minutes, $75 \mu \mathrm{L}$ of potassium carbonate solution at $7.5 \%$ were added and the mixture was kept at room temperature and protected from light for 40 minutes. The reading of absorbance was done in the UV-1230 spectrophotometer at $740 \mathrm{~nm}$. The results were calculated from a standard curve with known concentrations ( 5 to $80 \mu \mathrm{g} \cdot \mathrm{mL}^{-1}$ ) of gallic acid and expressed in $\mathrm{mg}$ of gallic acid (GA) per $g$ of lychee flour.

The scavenging capacity was determined using the free radical DPPH (2,2-diphenyl-1picrylhydrazyl), in triplicate ${ }^{11}$. In test tubes were added $66 \mu \mathrm{L}$ of the diluted extract of lychee at a concentration of 1:20 and $134 \mu \mathrm{L}$ of DPPH radical $0.5 \mathrm{mM}$ diluted in ethanol solution. The tubes were stirred and incubated for 45 minutes at room temperature and protected from light. The reading of absorbance was done in UV-1230 spectrophotometer at $517 \mathrm{~nm}$. The results were calculated from a standard curve with known concentrations (from 0.01 to $0.10 \mu \mathrm{Mol} \cdot 0.5 \mathrm{~mL}^{-1}$ ) of Trolox (6-hydroxy-2,5,7,8tetramethylchroman-2-carboxylic acid) and expressed as the Trolox equivalent scavenging capacity ( $\mu \mathrm{Mol}$ of TEAC per g of lychee flour) ${ }^{12}$.

The phenolic compounds and scavenging capacity analysis were performed in triplicate.

\section{Animal protocol}

Rats and diets

In biological assay were used 28 adult male rats, Rattus norvegicus species, Wistar lineage, from the Central Animal Laboratory of the Federal University of Viçosa, Campus Viçosa, with an initial weight of 250 to $300 \mathrm{~g}$. The animals were kept in individual cages at $22^{\circ} \mathrm{C}$, light/dark cycle of 12 hours (6:00 a.m. to 18:00 p.m.) and receiving feed and mineral water ad libitum. Following the description of diets: $\mathbf{C}$ $($ Control $)=100.00 \%$ Bio-tecBioBase ${ }^{\circledR}$ feed rats and mice $($ pellet $) ; \mathbf{H}($ Hypercaloric $)=$ $46.00 \%$ ground feed, $46.00 \%$ sweetened condensed milk, $8.00 \%$ corn oil; H2F (Hypercaloric with lychee flour $-50.00 \%$ peel and $50.00 \%$ seeds $)=43.00 \%$ ground feed, $43.00 \%$ sweetened condensed milk, $4.00 \%$ corn oil, $10.00 \%$ lychee flour; H3F (Hypercaloric with lychee flour $-33.33 \%$ peel, $33.33 \%$ pulp and $33.33 \%$ seeds $)=$ $43.00 \%$ ground feed, $43.00 \%$ sweetened condensed milk, $4.00 \%$ corn oil, $10.00 \%$ lychee flour. The experiment lasted for 16 weeks as shown in Figure 1. 


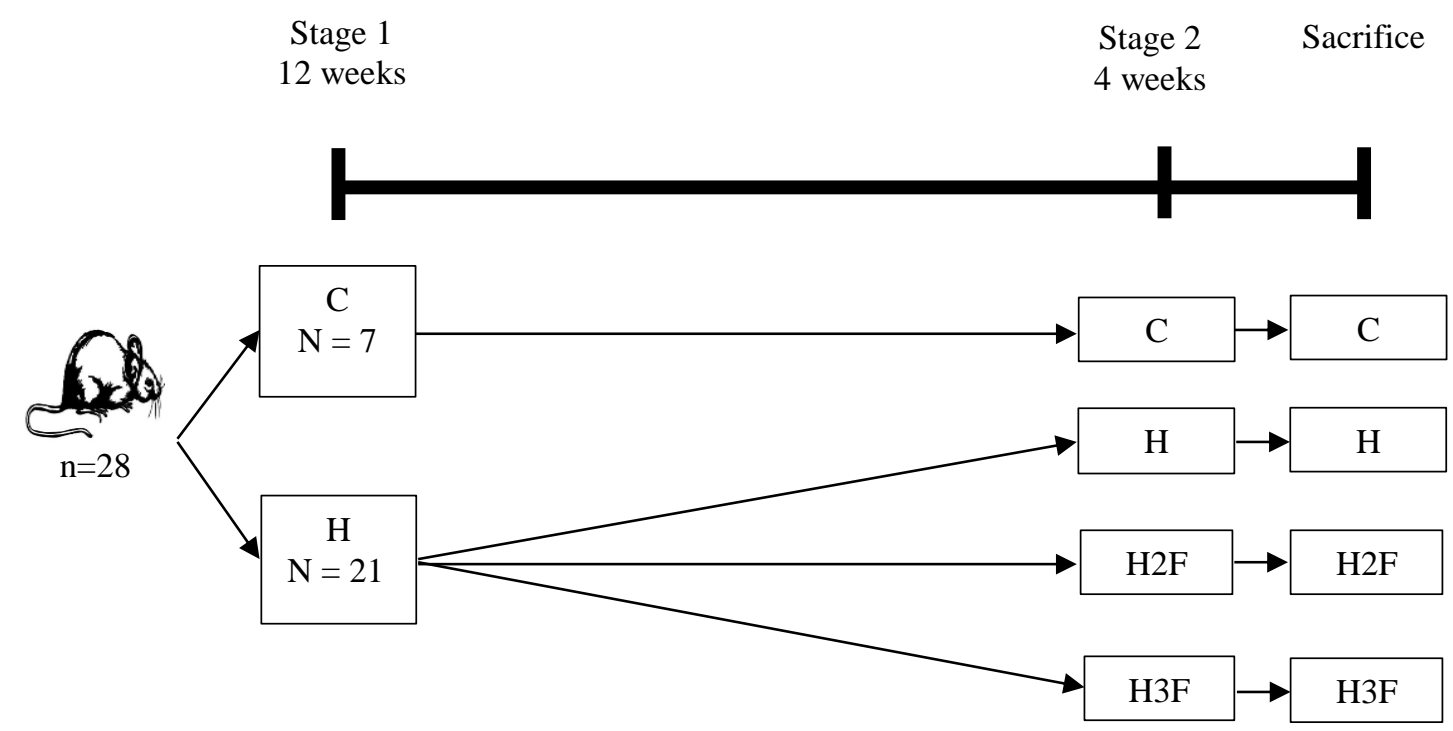

Figure 1. Schedule prepared for the experiment carried out with Wistar rats subjected to standard and cafeteria diets with lychee flour.

Food intake and apparent digestibility

The feed intake was calculated weekly based on difference between the quantity of food offered and the remains ${ }^{3}$. At the last week of lychee flour using, the feces were collected to calculate the diet apparent digestibility. Based on total of food intake and feces eliminated during two days was calculate the amount of nutrients absorbed by digestive tract, according to the equation: apparent digestibility = (quantity absorbed / quantity ingested) x 100 .

Morphometric parameters

The weight body and naso-anal distance were measured weekly ${ }^{3}$. From these data was calculated the Body Mass Index $=\left[\text { body weight }(\mathrm{g}) / \text { lenght }^{2}(\mathrm{~cm})\right]^{13}$, and the Lee Index $=[\text { body weight cube root }(\mathrm{g}) / \text { naso-anal size }(\mathrm{cm})]^{14}$.

It was proposed that the amount reduction of adipose tissue of groups fed with flour $(\mathrm{H} 2 \mathrm{~F}$ and $\mathrm{H} 3 \mathrm{~F})$ in comparison to the hypercaloric diet group $(\mathrm{H})$ was classified as: ineffective (0 to $4.99 \%)$, effective (5.00 to $9.99 \%)$ and excellent $(\geq 10.00 \%)$.

Sacrifice and collection of tissues

At the end of the experiment, the rats were submitted to general anesthesia with Propofol subcutaneously, into the flank region, at the rate of $10 \mathrm{~mL} \cdot \mathrm{kg}^{-1}$ of body weight. After the deep anesthesia, the animal was placed in the supine position and a gauze soaked with $70 \%$ alcohol was passed over the length of it. The thumb was slided on the animal's trunk until it was not more possible to feel the xiphoid cartilage. Then a needle at an angle of $45^{\circ}$ was introduced with a slope to the left. It was collected by cardiac puncture approximately $4 \mathrm{~mL}$ of blood that promoted the death by exsanguination under anesthesia.

The liver and epididymal and visceral tissues were removed for necropsy and weighed. The Hepatosomatic Index was determinate by the relation between liver weight and the body weight according to the equation ${ }^{15}$ : (liver weight/ body weight) $\mathrm{x} 100$. The Epididymal Fat Index was determined through the relation between epididymal adipose tissue and body weight of the rat according to the equation: (epididymal adipose tissue/ body weight) x 100. The Visceral Fat Index was determined by the relation between the weight of visceral adipose tissue and the body weight of the rat according to the equation: (visceral adipose tissue/ body weight) x 100 . 


\section{Compliance with ethics requirements}

All national and institutional guidelines for the careand use of laboratory animals were followed. This experiment was conducted according to the Ethical Principles in Animal Experimentation from Brazil, according to Law 11.794, of October 8, 2008. The project has been approved by the Ethics Committee on Animal Use of Federal University of Viçosa (protocol no 18/2014).

\section{Statistical analysis}

One-way analysis of variance was performed to evaluate the phenolic compounds and scavenging capacity. Significant differences $(p<0.05)$ between the treatments mean values were examined by Tukey's Test.

For in vivo assays the results were treated statistically using SPSS (Statistical Package for the Social Sciences, version 20.0). One-way variance analysis was applied. The differences between obtained mean values were examined by Tukey's Test at 5\% probability.

\section{RESULTS}

\section{Content of phenolic compounds and scavenging capacity}

The peel presented a higher $(\mathrm{p}<0.05)$ total phenolic content and scavenging capacity than other parts of the fruit (Table 1). The seed showed a higher antioxidant activity than the pulp $(p<0.05)$, but the pulp had a higher total phenolic content compared to the seed $(\mathrm{p}<0.05)$.

Table 1. Total phenolic content and lychee flour scavenging capacity.

\begin{tabular}{|c|c|c|}
\hline Samples & $\begin{array}{l}\text { Total phenolic content } \\
\left(\text { mg GAE } \cdot \text { g dry } \text { matter }^{-1}\right)\end{array}$ & $\begin{array}{l}\text { Scavenging capacity (TEAC) } \\
\left(\mu \mathrm{mol} \text { Trolox } \cdot \mathrm{g} \text { de dry matter }{ }^{-1}\right)\end{array}$ \\
\hline Peel & $25.10 \pm 1.15^{\mathrm{a}}$ & $43.80 \pm 2.02^{\mathrm{a}}$ \\
\hline Pulp & $20.30 \pm 1.45^{\mathrm{b}}$ & $13.20 \pm 1.52^{\mathrm{c}}$ \\
\hline Seed & $12.90 \pm 1.80^{c}$ & $21.40 \pm 1.98^{\mathrm{b}}$ \\
\hline
\end{tabular}

Mean and standard deviation with different letters in the same column differ significantly $(\mathrm{p}<0.05)$ by Tukey's Test.

\section{Food intake and apparent digestibility}

On stage 2 the groups food intake significantly differed in week 1 (Table 2), in which the control group was statistically higher than hypercaloric $(\mathrm{H})$ and hypercaloric groups fed with lychee flour $(\mathrm{H} 3 \mathrm{~F})(\mathrm{p}<0.05)$. However, was not founded difference in food consumption between hypercaloric groups $(\mathrm{H}, \mathrm{H} 2 \mathrm{~F}$ and $\mathrm{H} 3 \mathrm{~F})$ in weeks 1,2 and 3 . In weeks 2 and 3 the control group (C) showed a higher food intake compared to other groups $(\mathrm{p}<0.05)$. In week 4 the control group $(\mathrm{C})$ differed significantly only from the hypercaloric group $(\mathrm{H})$, showing that those who received the lychee flour $(\mathrm{H} 2 \mathrm{~F}$ and $\mathrm{H} 3 \mathrm{~F}$ ) had a similar intake compared to received the pelleted feed (C group).

Table 2. Food intake (g) of the Wistar rats on diet with lychee flour.

\begin{tabular}{ccccc}
\hline Groups & Week 1 & Week 2 & Week 3 & Week 4 \\
\hline C & $215.07 \pm 17.51^{\mathrm{b}}$ & $213.21 \pm 24.06^{\mathrm{b}}$ & $219.94 \pm 15.03^{\mathrm{b}}$ & $226.04 \pm 20.03^{\mathrm{b}}$ \\
H & $160.51 \pm 11.25^{\mathrm{a}}$ & $157.12 \pm 16.40^{\mathrm{a}}$ & $165.17 \pm 18.59^{\mathrm{a}}$ & $171.48 \pm 11.66^{\mathrm{a}}$ \\
H2F & $182.68 \pm 13.74^{\mathrm{ab}}$ & $169.27 \pm 17.44^{\mathrm{a}}$ & $159.08 \pm 11.29^{\mathrm{a}}$ & $219.35 \pm 18.69^{\mathrm{b}}$ \\
H3F & $164.73 \pm 11.19^{\mathrm{a}}$ & $168.37 \pm 13.03^{\mathrm{a}}$ & $173.80 \pm 24.08^{\mathrm{a}}$ & $205.67 \pm 16.28^{\mathrm{b}}$
\end{tabular}

Mean and standard deviation with different letters in the same column differ significantly $(\mathrm{p}<0.05)$ by Tukey's Test. $\mathrm{C}=\mathrm{Control} ; \mathrm{H}=$ Hypercaloric diet; $\mathrm{H} 2 \mathrm{~F}=$ Hypercaloric diet with lychee flour (peel and seed); H3F = Hypercaloric diet with lychee flour (peel, pulp and seed). 
The apparent digestibility of control diet (C) was significantly lower than other groups (Figure 2), demonstrating that the groups fed with hypercaloric diet show a better intestinal absorption of nutrients. There was no significant difference between the groups fed with hypercaloric diet $(\mathrm{H})$ and lychee flour $(\mathrm{H} 2 \mathrm{~F}$ e $\mathrm{H} 3 \mathrm{~F})$ highlighting that the flour does not interfere with nutrients absorption from diet.

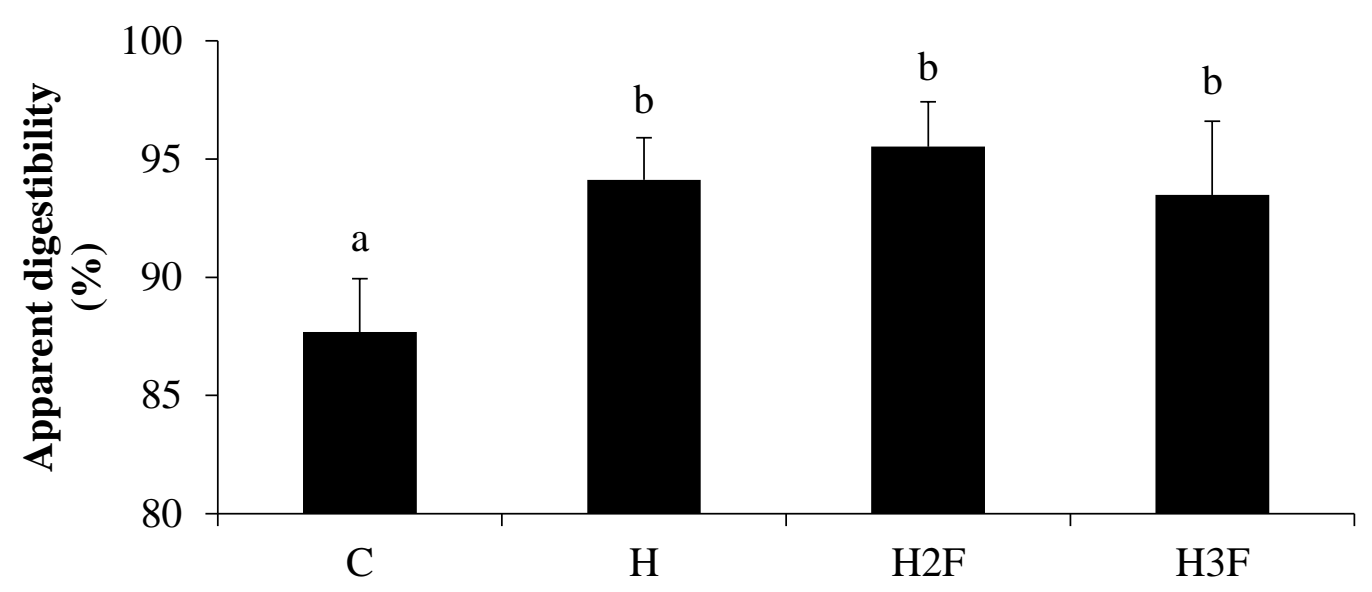

Figure 2. Apparent digestibility (\%) of the diet fed to Wistar rats. Mean and standard deviation with different letters in the same column differ significantly $(\mathrm{p}<0.05)$ by Tukey's Test. $\mathrm{C}=$ Control; $\mathrm{H}=$ Hypercaloric diet; $\mathrm{H} 2 \mathrm{~F}=$ Hypercaloric diet with lychee flour (peel and seed); H3F = Hypercaloric diet with lychee flour (peel, pulp and seed).

\section{Morphometric parameters}

No significant difference was observed at the end of the study between the groups related to body weight, Body Mass and Lee Index (Table 3), demonstrating that the flours in combination with hypercaloric diet did not change the morphometric parameters assessed.

Table 3. Body weight $(\mathrm{g})$, Body Mass Index $\left(\mathrm{g} / \mathrm{cm}^{2}\right)$, and Lee Index of the Wistar rats on diet with lychee flour.

\begin{tabular}{cccc}
\hline Parameters & Groups & Beginning & End \\
\hline \multirow{3}{*}{ Body weight } & C & $443.83 \pm 38.53$ & $477.55 \pm 50.01$ \\
& H & $497.02 \pm 29.69$ & $530.51 \pm 32.90$ \\
& H2F & $496.89 \pm 28.44$ & $519.92 \pm 29.31$ \\
H3F & $497.01 \pm 49.57$ & $522.30 \pm 46.90$ \\
\hline Body Mass Index & $\mathbf{C}$ & $0.69 \pm 0.06$ & $0.70 \pm 0.06$ \\
& H2F & $0.76 \pm 0.03$ & $0.76 \pm 0.03$ \\
& H3F & $0.75 \pm 0.04$ & $0.75 \pm 0.04$ \\
Lee Index & $\mathbf{C}$ & $0.75 \pm 0.06$ & $0.76 \pm 0.05$ \\
& H & $0.300 \pm 0.010$ & $0.298 \pm 0.009$ \\
& H2F & $0.309 \pm 0.004$ & $0.306 \pm 0.004$ \\
& H3F & $0.307 \pm 0.005$ & $0.306 \pm 0.007$ \\
\hline
\end{tabular}

There was no significant difference by Tukey's Test $(p>0.05)$ for all evaluated parameters.

There was no statistical difference between the groups regarding to liver weight (Figure $3)$. The control group (C) showed a lower quantity of epididymal and visceral tissues when compared to other groups. The groups fed with flour (H2F and $\mathrm{H} 3 \mathrm{~F})$ did not differ between themselves considering the visceral adipose tissue, however the group $\mathrm{H} 2 \mathrm{~F}$ (flour with peel and seed) showed a lower amount $(\mathrm{p}<0.05)$ of this tissue comparing to the group fed with hypercaloric diet (H) (Figure 3).

The highest amount of adipose tissue (epididymal and visceral) in the animals fed with hypercaloric diet, when compared with control group (C), associated to the absence of 
significant difference in final body weight shows that this diet is effective for promoting the increase in adipose tissue (Figure 3).

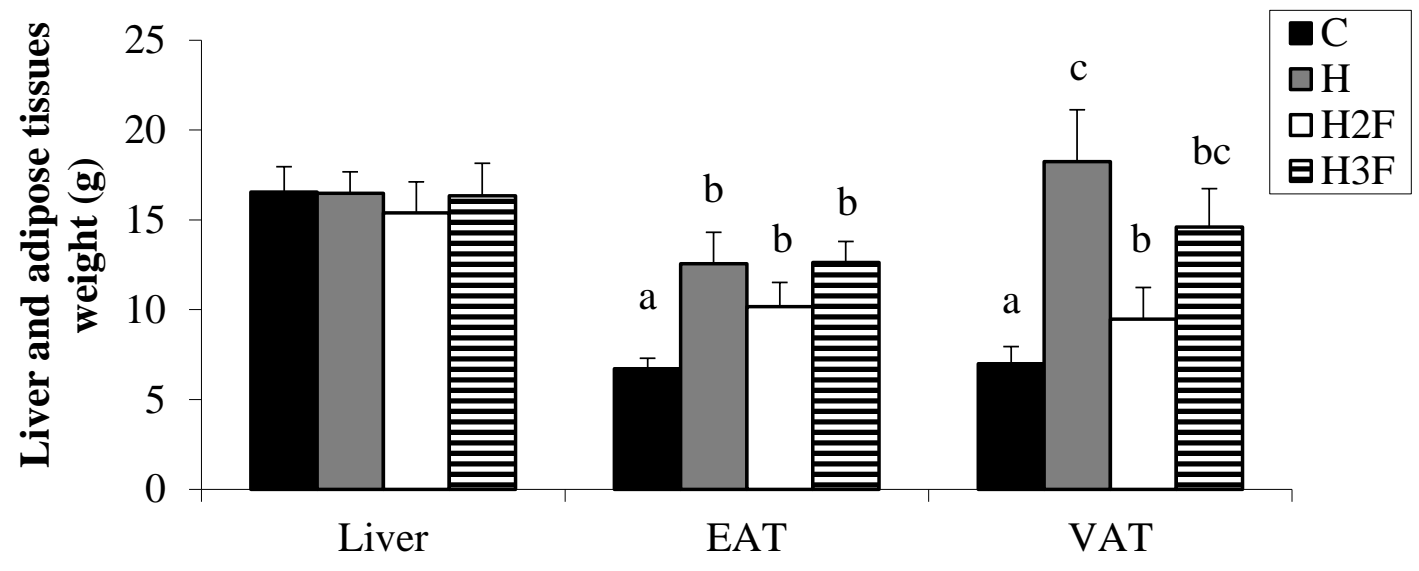

Figure 3. Liver (g) and epididymal and visceral adipose tissue (g) weight of the Wistar rats on diet with lychee flour. Mean and standard deviation with different letters in the same column differ significantly $(\mathrm{p}<0.05)$ by Tukey's Test. EAT $=$ Epididimal adipose tissue; VAT $=$ Visceral adipose tissue C $=$ Control; $\mathrm{H}=$ Hypercaloric diet; $\mathrm{H} 2 \mathrm{~F}=$ Hypercaloric diet with lychee flour (peel and seed); H3F = Hypercaloric diet with lychee flour (peel, pulp and seed).

When compared with the group $\mathrm{H}$, only hypercaloric diet with lychee flour (peel and seed - H2F) was classified as excellent, because it reduced $19.03 \%$ of epididymal adipose tissue, whereas the $\mathrm{H} 3 \mathrm{~F}$ group increased this tissue in $0.48 \%$. In both groups $\mathrm{H} 2 \mathrm{~F}$ and $\mathrm{H} 3 \mathrm{~F}$ the reduction of visceral adipose tissue was classified as excellent, the group with the peel and seed $(\mathrm{H} 2 \mathrm{~F})$ decreased $48.08 \%$ and the group with three pieces of fruit $(\mathrm{H} 3 \mathrm{~F})$ decreased $19.90 \%$.

The control group (C) presented a Hepatosomatic Index statistically higher than other groups (Figure 4) and was observed no significant difference between the groups treated with hypercaloric diet $(\mathrm{H}, \mathrm{H} 2 \mathrm{~F}$ and $\mathrm{H} 3 \mathrm{~F})$. The control group (C) showed lowest Epididymal fat and Visceral fat Index, while groups $\mathrm{H}$ and $\mathrm{H} 3 \mathrm{~F}$ showed highest Epididymal fat Index and did not differ between themselves, whereas the hypercaloric group $(\mathrm{H})$ presents the higher Visceral fat Index than the other groups.

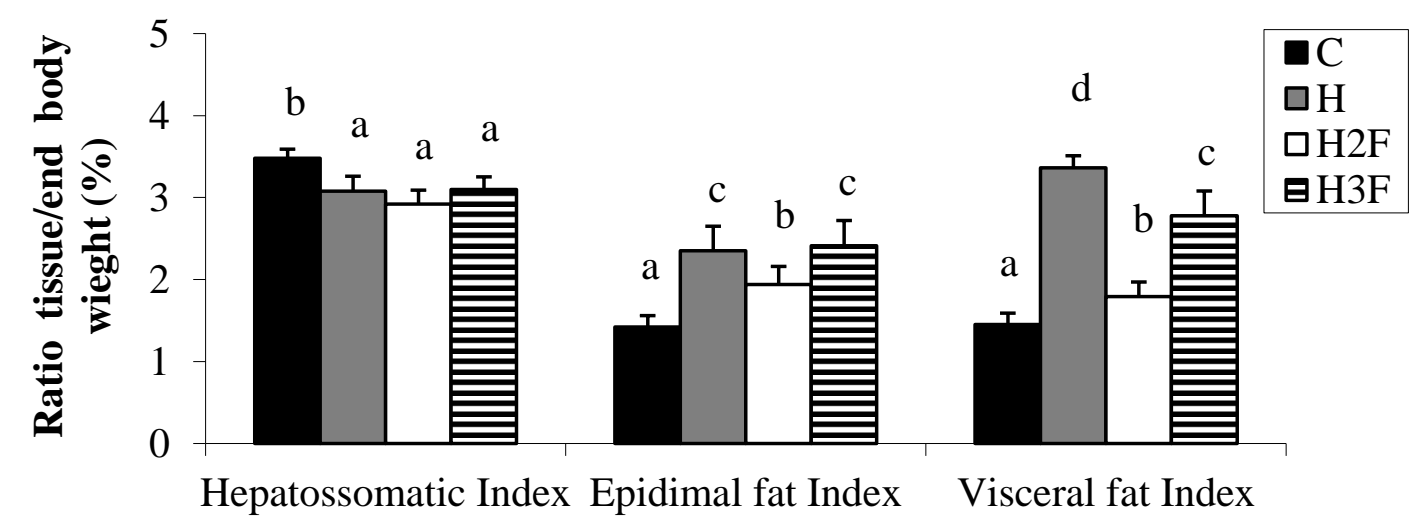

Figure 4. Hepatosomatic index (\%), epididymal fat index $(\%)$, and visceral fat index $(\%)$ of the Wistar rats on diet with lychee flour. Mean and standard deviation with different letters in the same column differ significantly $(\mathrm{p}<0.05)$ by Tukey's Test. $\mathrm{C}=$ Control; $\mathrm{H}=$ Hypercaloric diet; $\mathrm{H} 2 \mathrm{~F}=$ Hypercaloric diet with lychee flour (peel and seed); H3F = Hypercaloric diet with lychee flour (peel, pulp and seed).

The group fed with flour peel and pulp (H2F) showed lowest values of Epididymal and Visceral fat Index comparing to the groups $\mathrm{H}$ and $\mathrm{H} 3 \mathrm{~F}$, demonstrating that the peel and 
seed may contain a phytochemical that promoted the reduction of lipids from adipose tissues.

\section{DISCUSSION}

The peel of lychee had a higher content of phenolic compounds, and consequently a higher scavenging capacity (which is usually related to a high antioxidant activity) than the other parts of this fruit. This result can be explained by the amount of antioxidant compounds that contribute to the coloration of the skin lychee that normally are phenolic compounds, found frequently in peels of different fruits like apple, pineapple and mango, whose antioxidant activity is linked with molecules like quercetin and anthocyanins ${ }^{16}$.

The flour from the peel of lychee had higher phenolic content, beta-carotene, ascorbic acid, and antioxidant activity ${ }^{9}$, anthocyanins, proteins, lipids, ash and fiber ${ }^{6}$; while the seed flour is highlighted for the contents of licopeno ${ }^{9}$, potassium, sulfur, copper and zinc $^{6}$.

Presence of the highest amount of phenolic compounds and a lower scavenging capacity in the lychee pulp than in the seed can be explained by the lack of selectivity of the Folin-Ciocalteu method. This method considers the large number of phenolic compounds and several other reducing compounds, such as reducing sugars like fructose, present in the lychee pulp. However, these compounds lack scavenging capacity ${ }^{17}$.

$\mathrm{Li}$ et al. $(2012)^{18}$ identified range in pericarp of $9.39-30.16 \mathrm{mg} \mathrm{GAE} \cdot \mathrm{g}^{-1}$ in 9 varieties of lychee. Wang et al. (2011) $)^{19}$ emphasize that the lychee pericarp has high phenolics concentrations (51-102g. $\mathrm{kg}^{-1}$ of dry matter) modulating cell proliferation, neutralizing free radicals and regulating the activity of enzymes. The antioxidant activity, which is partly due to phenolic compounds, is essential to health, as it has anti-inflammatory activity of adipose tissue improving obesity and other diseases ${ }^{20,21}$.

In weeks 2 and 3, rats fed with a hypercaloric diet $(\mathrm{H})$ or hypercaloric diet with lychee flour $(\mathrm{H} 2 \mathrm{~F} \text { and H3F) demonstrated the lowest food intake. Eguchi et al. (2008) })^{22}$ reported that rats fed with hypercaloric diet usually ingest a higher amount of food when compared to animals that received standard pellets diet, resulting in an increase on body weight. Although the cafeteria diet is a good model for induction of obesity in animals, it can promote a voluntary hyperphagia owing to its palatability ${ }^{23}$. However, this behavior was not observed in our study because the rats fed with hypercaloric diet demonstrated a lower consumption rate than the control group (C) during the experimental weeks of the 4-week trial.

Food intake was the lowest diets rich in lipids were administered because of the inhibition of gastric emptying and increase in fatty acids oxidation. The possible mechanism for appetite suppression is reduction in digestion of carbohydrates and lipids in the digestive tract of the Wistar rats ${ }^{24}$. Sometimes the lowest food intake was associated with an increased caloric intake. This suggested that the Wistar rats were sensitive to diets rich in lipids and high energetic values, resulting in a low intake due the satiety ${ }^{25}$.

The apparent digestibility values indicated that hypercaloric diet-fed groups exhibited a greater utilization of ingested nutrients. It was found that both the obesity-resistant and obesity-prone rats, when treated with a high-fat diet, did not show differences in the digestibility of nutrients such as lipids, carbohydrates and proteins ${ }^{26}$.

In the end of the study there was no difference of body weight between the groups, differing from the Guo et al. (2004) ${ }^{27}$ in which there has been a decrease in rats body weight treated with lychee aqueous extract. The anti-obesity effects of lychee seed water extract were evaluated using an in vitro 3T3-L1 cell model, in which the extract 
inhibited the effect of lipase activities, and preadipocyte differentiation, and these effects were attributable to down-regulation of several adipogenesis-specific genes ${ }^{8}$. Lychee contains key bioactive phytochemicals that contribute directly or indirectly to its biological properties ${ }^{28}$. Oligonol, a compound extracted from lychee, has suffered industrial conversion to remain in its lowest molecular weight form to aide weight loss in humans. However, a study on standard diet-fed mice and that containing oligonol demonstrated no significant difference in body weight and food consumption ${ }^{29}$.

In the study performed by Almeida et al. $(2011)^{30}$, no significant difference in the Body Mass Index (BMI) and Lee Index was observed in rats subjected to a hypercaloric diet in comparison with the control rats. However, hypercaloric diet-fed rats demonstrated lower food intake, higher Lee Index, and increased body weight in comparison with the commercial diet-fed control group ${ }^{30}$.

As observed in another study, the liver weight did not differ significantly between the groups; however, a higher quantity of fat deposited on the liver was observed in cafeteria diet-fed rats ${ }^{31}$. This resulted in an increase in the liver's total weight in cafeteria diet-fed rats when compared with that of control rats ${ }^{22}$. A previous study had reported that the presence of toxic compounds in the diet can promote a significant increase or decrease in weight of liver ${ }^{32}$. However, our study demonstrated no significant change in liver weight, thus proving that lychee flour exhibits no toxicity, possesses liver tonic activity 5 .

The major amount of adipose tissues (epididymal and visceral) of hypercaloric diet-fed rats when compared with that of the control group (C) was found to be associated with the absence of a significant difference in the end body weight, thus showing that hypercaloric diet promoted an increase in adipose tissue mass. These results were similar to those of other studies ${ }^{33,34}$ in which a significant increase in epididymal and retroperitoneal adipose tissue mass was observed in rats subjected to hypercaloric diets. The intake of cafeteria diets with excess of macronutrients such as carbohydrates and lipids results in the accumulation of energy as fat ${ }^{35}$ specially the visceral and lesser extent to subcutaneous deposits ${ }^{22,35}$. It was possible to observed that several changes in Wistar rats fed with hypercaloric diets are related to increased abdominal adiposity (visceral) as a result of using this type of diet for a long time ${ }^{36}$. It is noticeable that the intra-abdominal adipose tissue, characterized by body fat around the visceral organs, is associate with the negative health effects regardless of the body fat amount ${ }^{37}$.

The control group (C) exhibited the higher Hepatossomatic Index and lowest Epididymal and Visceral fat Index as observed by Aloia et al. (2010) ${ }^{38}$.

The best indicator of obesity in hypercaloric diet-fed rats is body fat because body weight increases by approximately $10 \%$, while body fat increases by $30-50 \%^{37}$. The accumulation of adipose tissue has been associated to several markers of obesity such as weight gain, Body Mass Index and Lee Index ${ }^{37}$.

When compared with the group fed with only hypercaloric diet $(\mathrm{H})$, groups fed with $\mathrm{H} 2 \mathrm{~F}$ and $\mathrm{H} 3 \mathrm{~F}$ exhibited a decrease in epididymal and visceral adipose tissue mass. In the study of Chang et al. (2013) ${ }^{20}$ with polyphenols in the form of catechins oligomers and monomers and proanthocyanidins present in lychee, it was identified a reduction of body fat storage. Other studies show that the oligonol increased adiponectin production and decreased triglycerides accumulated in visceral adipose tissue of rats ${ }^{29}$, stimulated lipolysis by regulating an extracellular kinase (ERK1/2) accompanied by a decrease of perilipina levels ${ }^{39}$ and reduced fat cytosolic content and lipogenic gene expression ${ }^{40}$. Lychee seed water extract decreased the epididymal adipose tissue sizes as well as serum and liver lipid contents which partially resulted from increased fecal lipid excretion ${ }^{41}$.

The lychee fruit, with a relatively high antioxidant content, has potential health benefits and is considered as a functional food because of the presence of bioactive compounds that have anti-inflammatory properties. Polyphenols (in the form of monomers and 
oligomers of catechins) and proanthocyanidins have a significant effect on the metabolic syndrome, type 2 diabetes, by preventing and reducing fat reserves ${ }^{20}$.

Daily consumption of $200 \mathrm{mg}$ of oligonol for 10 weeks in 18 Japanese volunteers, aged 24-59 years, resulted in a significant reduction in Body Mass Index and fat tissue mass, along with a decrease of $15 \%$ of visceral and $6 \%$ of the subcutaneous fat ${ }^{42}$.

The peel of the lychee contains a large amount of flavonoids and polyphenols; therefore, the flour of this fruit part has a higher concentration of antioxidants than the fresh fruit ${ }^{7,43}$. The seed contains proanthocyanidins, flavonoids, steroids, and sesquiterpenes ${ }^{44}$, and therefore, can be used as a natural source of antioxidants.

In this study, the effect of lychee flour was observed only for four weeks. This could be considered as a limitation. Further studies need be performed for a longer treatment period to understand the long-term effects of the flour on rats, as well as other animal models.

\section{CONCLUSION}

The lychee peel was found to have higher amounts of phenolic compounds and scavenging capacity. The hypercaloric diet in combination with lychee flour resulted in a higher apparent digestibility. No significant difference in the Body Mass Index, Lee Index, and liver weight was observed between groups during the use of lychee flour alone. The flour, in combination with a hypercaloric diet, was found to be ineffective in decreasing the final weight of the rats. However, the peel and seed flour reduced the amount of visceral adipose tissue deposition. The use of the lychee flour (peel and seeds) in the diet was considered viable because of the decrease in visceral adipose tissue mass.

\section{REFERENCES}

1. Leite FSC, Farias TC, Moura GD, Maia VT. Metabolic syndrome and eating habits: approach to diet and co-factors associated with the emergence of the metabolic syndrome in patients seen in cardiology clinic in Sorocaba-SP - Cardio Center. Rev. Bras. Obes. Nutr. Emagrec. 2010; 4:130-136.

2. Wu T, Luo J, Xu B. In vitro antidiabetic effects of selected fruits and vegetables against glycosidase and aldose reductase. Food Sci. Nutr. 2015; 3:495-505.

3. Almeida MEF, Simão AA, Corrêa AD, Fernandes RVB. Improvement of physiological parameters of rats subjected to hypercaloric diet, with the use of Pereskia grandifolia (Cactaceae) leaf flour. Obes. Res. Clin. Pract. 2016; 10:701-709.

4. Naderali EK, Pickavance LC, Wilding JPH, Williams G. Diet induced endothelial dysfunction in the rat is dependent of the degree of increase in total body weight. Clin. Sci. 2001; 100:635-641.

5. Bhoopat L, Srichairatanakool S, Kanjanapothi D, Taesotikul T, Thananchai H, Bhoopat T. Hepatoprotective effects of lychee (Litchi chinensis Sonn.): a combination of antioxidant and anti-apoptotic activities. J. Ethnopharmacol. 2011; 136:55-66.

6. Queiroz ER, Abreu CMP, Santos CM, Simão AA. Chemical and phytochemical composition of flours from skin and seeds of 'Bengal' lychee (Litchi chinensis Sonn). Cienc. Rural 2015; 45:329-334.

7. Man S, Ma J, Wang C, Li Y, Gao W, Lu F. Chemical composition and hypoglycaemic effect of polyphenol extracts from Litchi chinensis seeds. J. Funct. Foods 2016; 22:313324.

8. Qi S, Huang H, Huang J, Wang Q, Wei Q. Lychee (Litchi chinensis Sonn.) seed water extract as potential antioxidant and anti-obese natural additive in meat products. Food Control. 2015; 50:195-201.

9. Queiroz ER, Abreu CMP, Oliveira KS, Ramos VO, Fráguas RM. Bioactive phytochemicals and antioxidant activity in fresh and dried lychee fractions. Rev. Ciênc. Agron. 2015; 46:163-169. 
10. Singleton VL, Orthofer R, Lamuela-Raventás RM. Analysis of total phenols and other oxidation substrates and antioxidants by means of Folin-Ciocalteu reagent. Methods Enzymol. 1999; 299:152-178.

11. Brand-Williams W, Cuvelier ME, Berset C. Use of free radical method to evaluate antioxidant activity. LWT - Food Sci. Technol. 1995; 28:25-30.

12. Al-Duais M, Müller L, Böhm V, Jetschke G. Antioxidant capacity and total phenolics of Cyphostemma digitatum before and after processing: use of different assays. Eur. Food Res. Technol. 2009; 228:813-821.

13. Novelli ELB, Diniz YS, Galhardi CM, Ebaid GMX, Rodrigues HG, Mani F, et al. Anthropometrical parameters and markers of obesity in rats. Lab. Animals 2007; 41:111-119.

14. Bernardis LL, Patterson BD. Correlation between 'Lee Index' and carcass fat content in weanling and adult female rats with hypothalamic lesions. J. Endocrinology 1968; 40:527-528.

15. Leite MAG. Influência do tanino sobre a concentração de colesterol em ratos submetidos à ingestão de dieta rica em lipídios [mestrado]. Araraquara: Universidade Estadual Paulista. 2003.

16. Oliveira AC, Valentim IB, Goulart MOF, Silva CA, Bechara EJH, Trevisan MTS. Vegetals as natural sources of antioxidants. Quím. Nov. 2009; 32:689-702.

17. Oliveira AC, Valentim IB, Silva CA, Bechara EJH, Barros MP, Mano CM, et al. Total phenolic content and free radical scavenging activities of methanolic extract powders of tropical fruit residues. Food Chem. 2009; 115:469-475.

18. Li W, Liang H, Zhang MW, Zhang RF, Deng YY, Wei ZC, et al. Phenolic profiles and antioxidant activity of litchi (Litchi chinensis Sonn.) fruit pericarp from different commercially available cultivars. Molecules 2012; 17:14954-14967.

19. Wang H-C, Hu Z-Q, Wang Y, Chen H-B, Huang X-M. Phenolic compounds and the antioxidant activites in litchi pericarp: difference among cultivars. Sci. Hort. 2011; 129:784-789.

20. Chang Y-Y, Yang D-J, Chiu C-H, Lin Y-L, Chen J-W, Chen Y-C. Antioxidative and anti-inflammatory effects of polyphenol-rich litchi (Litchi chinensis Sonn.)-flowerwater-extract on livers of high-fat-diet fed hamsters. J. Funct. Foods 2013; 5:44-52.

21. Siriwardhana N, Kalupahana NS, Cekanova M, LeMieux M, Greer B, MoustaidMoussa N. Modulation of adipose tissue inflammation by bioactive food compounds. J. Nutr. Biochem. 2013; 24:613-623.

22. Eguchi R, Cheik NC, Oyama LM, Nascimento CMO, Mello MT, Tufik S, et al. Effects of the chronic exercise on the circulating concentration of leptin and ghrelin in rats with diet-induced obesity. Rev. Bras. Med. Esporte 2008; 14:182-187.

23. Colombo G, Bazzo ML, Nogueira CL, Colombo MDHP, Schiavon LL, d'Acampora AJ. A study on the short-term effect of cafeteria diet and pioglitazone on insulin resistance and serum levels of adiponectin and ghrelin. Braz. J. Med. Biol. Res. 2012; 45:935-941.

24. Shivaprasad HN, Gopalakrishna S, Mariyanna B, Thekkoot M, Reddy R, Tippeswamy BS. Effect of Coleus forskohlii extract on cafeteria diet-induced obesity in rats. Pharmacognosy Res. 2014; 6:42-45.

25. Speretta E, Jahn TR, Tartaglia GG, Favrin G, Barros TP, Imarisio S, et al. Expression in drosophila of tandem amyloid $\beta$ peptides provides insights into links between aggregation and neurotoxicity. J. Biol. Chem. 2012; 287:20748-20754.

26. Cabeço LC, Akiba M, Calsa MS, Sartori DRS, Vicentini-Paulino MLM, Pinheiro DF. High-fat diet using soybean meal as protein source: use for selecting rats prone and resistant to obesity. Rev. Nutr. 2010; 23:417-424.

27. Guo J, Li L, Pan J, Qiu G, Li A, Huang G, Xu L. Pharmacological mechanism of semen litchi on antagonizing insulin resistance in rats with type 2 diabetes. Zhong Yao Cai 2004; 27:435-438.

28. Ibrahim SR, Mohamed GA. Litchi chinensis: medicinal uses, phytochemistry, and pharmacology. J. Ethnopharmacol. 2015; 174:492-513.

29. Fujii H, Nishioka H, Wakame K, Magnuson BA, Roberts A. Acute, subchronic and genotoxicity studies conducted with oligonol, an oligomerized polyphenol formulated from lychee and green tea extracts. Food Chem. Toxicol. 2008; 46:3553-3562. 
30. Almeida MEF, Medeiros RS, Figueiredo FJB, Coelho EJB, Sena MPT. Effect of auditory stress and high calorie diet on body weight, lipids and glycemia in wistar rats. Alim. Nutr. 2011; 22:359-365.

31. Macedo IC, Medeiros LF, Oliveira C, Oliveira CM, Rozisky JR, Scarabelot VL, et al. Cafeteria diet-induced obesity plus chronic stress alter serum leptin levels. Peptides 2012; 38:189-196.

32. Bardocz S, Grant G, Pusztai A. The effect of phytohaemagglutinin at different dietary concentrations on the growth, body composition and plasma insulin of the rat. Br. $J$. Nutr. 1996; 76:613-626.

33. Duarte ACGO, Fonseca DF, Manzoni MSJ, Soave CF, Sene-Fiorese M, Dâmaso AR, et al. High-fat diet and secretory capacity of insulin in rats. Rev. Nutr. 2006; 19:341348.

34. Rosa DD, Sales RL, Moraes LFS, Lourenço FC, Neves CA, Sabarense CM, et al. Flaxseed, olive and fish oil influence plasmatic lipids, lymphocyte migration and morphometry of the intestinal of Wistar rats. Acta Cir. Bras. 2010; 25:275-280.

35. Marosti AR, Almeida FN, Moraes SMF, Molinari SL, Natali MRM. Effects of the cafeteria diet on the salivary glands of trained and sedentary Wistar rats. Acta Scient. Biol. Sci. 2012; 34:113-118.

36. Nascimento AF, Sugizaki MM, Leopoldo AS, Lima-Leopoldo AP, Nogueira CR, Novelli ELB, et al. Misclassification probability as obese or lean in hypercaloric and normocaloric diet. Biol. Res. 2008; 41:253-259.

37. Costa CAS, Alves EG, Gonzalez GP, Barbosa TBC, Lima VD, Nascimento R, et al. Computed tomography in the evaluation of abdominal fat distribution associated with a hyperlipidic diet in previously undernourished rats. Radiol. Bras. 2007; 40:337-340.

38. Aloia TPA, Cogliati B, Guerra RR, Parra OM, Dagli MLZ, Hernandez-Blazquez FJ. Model of nutritional supplementation with hepatotrophic factors increases cell proliferation in the liver of healthy rats. Arq. Bras. Med. Vet. Zootec. 2010; 62:853-861.

39. Ogasawara J, Kitadate K, Nishioka H, Fujii H, Sakurai T, Kizaki T, et al. Oligonol, a new lychee fruit-derived low-molecular form of polyphenol, enhances lipolysis in primary rat adipocytes through activation of the ERK1/2 pathway. Phytotherapy Res. 2009; 23:1626-1633.

40. Park JY, Kim Y, Im JA, You S, Lee H. Inhibition of adipogenesis by oligonol through Akt-mTOR inhibition in 3T3-L1 adipocytes. Evid. Based Complement. Alternat. Med. 2014; 14:1-11.

41. Wu YS, Chiu C, Yang D, Lin Y, Jung-Kai T, Chen Y. Inhibitory effects of litchi (Litchi chinensis Sonn.) flower-water extracts on lipase activity and diet- induced obesity. $J$. Funct. Foods 2013; 5:923-929.

42. Noh JS, Park CH, Yokozawa T. Treatment with oligonol, a low- molecular polyphenol derived from lychee fruit, attenuates diabetes-induced hepatic damage through regulation of oxidative stress and lipid metabolism. Br. J. Nutr. 2011; 106:1013-1022.

43. Jiang G, Lin S, Wen L, Jiang Y, Zhao M, Chen F, et al. Identification of a novel phenolic compound in litchi (Litchi chinensis Sonn.) pericarp and bioactivity evaluation. Food Chem. 2013; 136:563-568.

44. Xu X, Xie H, Hao J, Jiang Y, Wei X. Flavonoid glycosides from the seeds of Litchi chinensis. J. Agric. Food Chem. 2011; 59:1205-1209. 